\title{
The persistent southern tomato virus modifies miRNA expression without inducing symptoms and cell ultra-structural changes
}

\author{
Laura Elvira-González • Vicente Medina • \\ Luis Rubio • Luis Galipienso
}

Accepted: 2 December 2019/Published online: 18 December 2019

(C) Koninklijke Nederlandse Planteziektenkundige Vereniging 2019

\begin{abstract}
Southern tomato virus (STV) is a doublestranded RNA virus (genus Amalgavirus, family Amalgaviridae) with a persistent lifestyle, transmitted only vertically by seed. STV is widely distributed showing a high incidence in tomato crops from different production regions. Acute viruses usually induce plant development and cell ultra-structural changes related to the production of plant symptoms. Some of these changes are the consequence of alterations in the expression of endogenous plant microRNAs (miRNAs) and generation of viral small interfering RNAs (vsiRNAs) which play substantial roles in plant gene expression regulation. Most cryptic or persistent viruses do not induce symptoms. However, the effect of infection of persistent viruses on their hosts has been poorly studied. In this work, high-throughput sequencing of small RNAs revealed a differential expression of five miRNAs in STVinfected tomato plants: four were upregulated (stu-
\end{abstract}

Electronic supplementary material The online version of this article (https://doi.org/10.1007/s10658-019-01911-y) contains supplementary material, which is available to authorized users.

L. Elvira-González • L. Rubio · L. Galipienso $(\bowtie)$

Centro de Protección Vegetal y Biotecnología, Instituto

Valenciano de Investigaciones Agrarias (IVIA), CV-315, Km 10.

46113, Moncada, Spain

e-mail: galipienso_lui@gva.es

L. Elvira-González

Universitat Politècnica de València (UPV), Valencia, Spain

V. Medina

Departamento Producció Vegetal i Ciència Forestal, Universitat de Lleida, Lleida, Spain
miR398 - 3p, stu-miR398-5p, stu-miR3627-3p, and stumiR408b-5p) and one downregulated (stu-miR319-3p). Target prediction analysis and GO function annotations of the host target genes suggest that those miRNAs are involved in complex cellular pathways such as response to different stress conditions and defence against pathogens. In contrast to acute plant virus infections, only a few STV derived vsiRNAs were found. Finally, neither symptoms, cell ultra-structural changes nor virus particles were observed in STV-infected tomato leaf tissues. These results suggest a complex interaction of STV with its tomato host.

Keywords STV·Amalgaviridae $\cdot$ High-throughput sequencing $\cdot$ miRNA $\cdot$ Microscopy

\section{Introduction}

The recent development of deep sequencing techniques enables discovering new viruses in plants and reveals that plants are frequently infected by persistent or cryptic viruses. These viruses have been scarcely studied and the effect on their hosts is poorly understood. Plants infected with persistent viruses remains infected during all its life cycle (Roossinck 2010) and some of them establish symbiotic relationships. Thus, white clover cryptic virus 1 can generate benefits in clover plants during high nitrogen levels by modulating the nodulation process (Roossinck 2011) or Curvularia thermal tolerance virus enables the fungus Curvularia protuberata to confer thermal tolerance to the panic 
grass (Panicum sp.) and grow in soils with temperatures over $50{ }^{\circ} \mathrm{C}$ (Marquez et al. 2007).

In contrast, acute viruses establish a parasitic relationship with their host, frequently causing alterations in the plant phenotype (i.e. leaf yellowing or mosaics, stunting, fruit discoloration or malformations) and the cell ultrastructure (ex. cytoplasmic vesicle generation involved on virus replication) (Medina et al. 2003). Some of these alterations are consequence of expression changes of plant microRNAs (miRNAs) involved in many developmental processes and stress responses during viral infection (Dunoyer and Voinnet 2005). For example, the populations of miR159/319 and miR172 in tomato are modified during infection by tomato leaf curl New Delhi virus (Naqvi et al. 2010) and the populations of miR163, miR164 and miR167 in Arabidopsis thaliana change by infection by tomato mosaic virus (Tagami et al. 2007). Also, the viral small interfering RNAs (siRNAs) produced by RNA silencing, a plant defence mechanism, can target and regulate host genes in a post-transcriptionally way (Huang et al. 2016). Recently, experimental evidences confirmed that vsiRNAs derived from some acute viruses such as cucumber mosaic virus (CMV) or tomato yellow leaf curl virus (TYLCV) regulate the expression of host genes and modulate viral disease symptoms (Smith et al. 2011; Yang et al. 2019). To gain insight into these processes for persistent viruses we have studied the effect of southern tomato virus (STV) infection in tomato (Solanum lycopersicum).

STV is the type member of the genus Amalgavirus (family Almalgaviridae), which also contains blueberry latent virus, Rhododendron virus A and Vicia cryptic virus M (Gandía et al. 2007; Martin et al. 2011; Sabanadzovic et al. 2009). STV has a persistent lifestyle and differs from acute viruses in that it is only transmitted by seed at very high rates (up to $80 \%$ ) (Elvira-González et al. 2017; Sabanadzovic et al. 2009). STV genome is a double-stranded RNA (dsRNA) of $3.5 \mathrm{~kb}$ in length with two overlapping open reading frames, the 5 '-proximal encoding for a putative coat protein and the 3'-proximal encoding for the RNAdependent RNA polymerase. Until now, no silencing suppressor activity has been identified in the two STV encoded proteins. No viral particles have been observed in STV-infected tissues under electron microscopy (Sabanadzovic et al. 2009).

STV was reported in plants showing different symptoms such as stunting, leaf yellowing and discolouration and fruit size reduction from different production areas such as Mexico, United States, Italy, France, Spain, China and Bangladesh. Most of these plants were coinfected with acute viruses which could cause such symptoms. Also, biological assays and surveys of STV in field revealed that plants infected only by STV did not show any symptoms (Elvira-González et al. 2017, 2018; Puchades et al. 2017). Recently, a mutualistic relationship of STV with its tomato host has been reported (Fukuhara et al. 2019).

In this work, the effect of STV single infections in tomato plants was studied through a comparative study between STV-infected and uninfected plants. Highthroughput small RNA sequencing was used to analyse the miRNA and vsiRNA populations. Also, optical and transmission electron microscopy (TEM) was used to analyse the cellular ultra-structure and the presence of viral particles associated to STV infection.

\section{Material and methods}

A total of 85 commercial hybrid seeds of tomato var. Roque were germinated in a Petri dish. Each seedling was transplanted to an individual flower pot and grown in a chamber with controlled temperature $\left(25^{\circ} \mathrm{C}\right)$ and light cycle (16 h light/ $8 \mathrm{~h}$ dark). Total RNA was extracted with the Spectrum TM Plant total RNA Kit (Sigma, Missouri, USA) at 15 days and 20 days after the development of the first leaf. The presence or absence of STV was assessed by quantitative reverse transcription PCR (RT-qPCR) using a set of STV specific primers and a Taqman probe (Elvira-González et al. 2018). Thus, the tomato plants were classified in two groups, STVinfected and uninfected plants which were used as experimental controls.

For the elaboration of small RNA libraries, three biological replicates from STV-infected and three from uninfected tomato plants were analysed. Each replicate consisted of a mix of total RNA extracts obtained from three individual tomato plants at 15 days after the development of the first true leaf. RNA concentration and purity were determined by using the Qubit ${ }^{\circ}$ RNA Assay Kit in a Qubit® 3.0 Fluorometer (Thermo Fisher Scientific, Massachusetts, USA) and by using the NanoPhotometer ${ }^{\circledR}$ spectrophotometer (IMPLEN, California, USA), respectively. RNA integrity was analysed in the Agilent Bioanalyzer 2100 system with the RNA Nano 6000 Assay Kit (Agilent Technologies, California, 
USA). cDNAs were obtained from $1 \mu \mathrm{g}$ of total RNA of each biological replicate by using the NEBNext® Multiplex Small RNA Library Prep Set for Illumina® (Sigma Aldrich, Missouri, USA) and sequenced by using the Illumina NextSeq550 platform (Illumina, California, USA). Library data has been uploaded to the NCBI platform and published under accession number PRJNA574043. Reads were cleaned by trimming the sequencing adapters and low-quality reads were filtered by using SeqTrimNext software applying the standard parameters for Illumina short reads (Falgueras et al. 2010). The length of the reads was restricted from 15 to 32 nucleotides (nt).

Identification and quantitation of miRNAs were performed through Oasis 2.0 pipeline analysis: reads were aligned with the STAR program in the database RNAbase 2.1 (ftp://mirbase.org/pub/mirbase/), the known miRNAs were quantified with the FeatureCounts program whereas the prediction and quantification of novel miRNA were done with the miRDeep2 program (Rahman et al. 2018). Differential expression of miRNAs was analysed with the algorithm DESeq2 but previously, the correlation among the different biological replicates was determined by Principal Component Analysis. A log fold-change was considered statistically significant when its expression foldchange was at least double $(|\log \mathrm{F}|>1)$ with an FDR $<$ 0.05 . The target genes of miRNAs showing differential accumulation were predicted by using the psRNAtarget online tool (http://plantgrn.noble.org/psRNATarget/) with the $S$. lycopersicum transcriptome v 3.2. Targets with scores $<4.0$ were considered as potential target genes whose functions were assigned by the Gene Ontology (GO) and Kyoto Encyclopedia of Genes and Genomes analysis in conjunction with Uni-protKB and the National Center for Biotechnology Information database. The resulting clean reads were mapped to the STV isolate GCN06 (KJ174690) (Verbeek et al. 2015) using Bowtie v2.1.0 (the version required by RepEnrich), and then sorted and indexed using SAMtools, to obtain one sorted BAM file and one FastQ file containing the multi-mapping reads for each sample (Ziemann et al. 2016).

STV-infected and uninfected tomato leaf tissues were analysed by optical and TEM. Small leaf pieces $(0.1 \times$ $1 \mathrm{~cm}$ ) were fixed with $2.5 \%$ glutaraldehyde solution in $0.1 \mathrm{M}$ buffer phosphate $(\mathrm{pH} 7.2)$ solution for 16-24 h. Then, they were washed in $0.1 \mathrm{M}$ phosphate buffer for $1 \mathrm{~h}$ and post-fixed with $2 \%$ osmium tetroxide (pH: 7.2) for $2 \mathrm{~h}$.
Fixed tissues were dehydrated with ethanol in increasing concentration series (from 30 to $100 \%$ ) and stained with $1 \%$ uranyl acetate. Finally, leaf tissues were embedded in Araldite resin and processed into semi-thin and ultra-thin sections for optical and electron microscopy, respectively. Semi-thin sections were stained with Richardson's blue and examined with an optical microscope (Nikon Eclipse E600) whereas ultra-thin sections were stained with $1 \%$ uranyl acetate and examined with a Philips CM10 TEM at 60 KV (Alfaro-Fernández et al. 2010).

For virion isolation, STV infected tomato leaf tissues were homogenised with extraction buffer $(0.25 \mathrm{M}$ potassium phosphate, $\mathrm{pH} 7.0$ and $0.1 \%$ 2-mercaptoethanol), filtrated with mousseline and centrifuged at $8000 \times \mathrm{g}$ for $10 \mathrm{~min}$ in $1 \%$ Triton X-100 solution. The supernatant was collected and polyethylene glycol (PEG 6000) and sodium chloride were added to final concentrations of 8 and $1 \%$, respectively. After agitation for $2 \mathrm{~h}$ on ice, it was centrifuged $8000 \times \mathrm{g}$ for $10 \mathrm{~min}$ and the supernatant was collected and ultra-centrifuged at $235000 \times \mathrm{g}$ for $3 \mathrm{~h}$ in a $15 \%$ of sucrose cushion. The pellet was re-suspended in extraction buffer and Carbon-Formvar coated grids were floated for 10-15 min on a drop of extract resuspension, rinsed with distilled water, stained with $1 \%$ uranyl acetate and examined in a Philips CM 10 TEM at $60 \mathrm{KV}$.

\section{Results and discussion}

To select nine STV-infected and nine uninfected tomato plants, 85 seedlings were analysed by RT-qPCR at 15 days after the development of the first true leaf from. The nine selected STV-infected plants showed threshold cycles ranging from 21 to 24, whereas uninfected plants show no signal (Supplementary File 1). Identical results were obtained at 20 days after the development of the first true leaf (data not shown).

siRNAs mediate important biological functions in plants which include development, cell proliferation, adaptation to stress, apoptosis and signal transduction (Li et al. 2012; Sun 2012). siRNAs are also involved in plant defence against pathogens by regulating the resistance genes or preventing viral replication (Liu et al. 2017; Wang et al. 2012). Hence, the siRNA pathway plays a key role during pathogen-plant interactions. High-throughput sequencing of small RNAs was used to study the influence of STV infection on siRNA populations in tomato plants (Table 1). siRNA read lengths ranged from $15 \mathrm{nt}$ to $32 \mathrm{nt}$ but most of them from $21 \mathrm{nt}$ 
Table 1 Results of small RNAs throughput sequencing from STV-infected and uninfected tomato plants

\begin{tabular}{lllll}
\hline Samples & Input Reads & Output Reads & Rejected & $\%$ Rejected \\
\hline Uninfected 1 & $1,4 \mathrm{E}+07$ & $1,1 \mathrm{E}+07$ & $2,601,857$ & 19.06 \\
Uninfected 2 & $9,086,155$ & $7,512,326$ & $1,573,829$ & 17.32 \\
Uninfected 3 & $5,448,190$ & $4,256,600$ & $1,191,590$ & 21.87 \\
STV-infected 1 & $5,280,185$ & $3,816,253$ & $1,463,932$ & 27.73 \\
STV-infected 2 & $1,3 \mathrm{E}+07$ & $1,1 \mathrm{E}+07$ & $2,148,519$ & 16.56 \\
STV-infected 3 & $9,810,832$ & $7,843,693$ & $1,967,139$ & 20.05 \\
\hline
\end{tabular}

to $24 \mathrm{nt}$, which are produced by Dicer-Like 4 and RNA dependent RNA polymerase 6 at the first and subsequent steps of the RNA gene silencing pathway (Niu et al. 2015). Five miRNAs showed a differential expression $($ FDR < 0.05): miRNAs stu-miR398-3p, stumiR398-5p, stu-miR3627-3p and stu-miR408b-5p were upregulated and stu-miR319-3p was downregulated in STV-infected tomato plants compared to the uninfected ones (Table 2). Four of those miRNAs corresponded to potential novel RNAs in tomato described from potato (S. tuberosum) which belongs to the same genus as tomato (stu-miR398-3p/5p, stu-miR3627-3p and stumiR319-3p) (Supplementary File 2).

Eighty-seven target genes were predicted for the five plant miRNA expressed deferentially in STV-infected tomato plants. Tentative functions of 58 out of 87 targeted plant genes were successfully annotated by GO analysis (Supplementary File 2). Biological roles of these genes involve a complex network of cellular pathways such as metabolic and cell redox homeostasis, intracellular transport, cytoplasmic vesicle formation, cytoskeleton and ribosomal structuration. Also, 10 of the targeted genes encode for transcription factors that regulate the expression of functional genes. The tomato miRNAs slymiR169e-3p, which is downregulated in STV-infected tomato plants, is related to plant development and stress (Blevins et al. 2011; Zhao et al. 2017). Also, the miR169e has orthologues in other plant species such as
Arabidopsis thaliana, Zea mays, Oryza sativa, Populus trichocarpa, Sorghum bicolor and Glycine max (Parish and $\mathrm{Li}$ 2012). In this last species, miR169e was upregulated during chilling stress ( $\mathrm{Xu}$ et al. 2016). The stumiR319-3p was identified in potato and coffee (Coffea arabica) but its function and the effect in both plant species is unknown (Chaves et al. 2015).

Only a few STV-derived 21-nt and 22 nt vsiRNAs were detected in STV-infected tomato plants (14, 77 and 53 reads for the three plant replicates). A few read sequences aligning with the STV genome were detected in the uninfected tomato plants $(25,32$ and 17 reads for the three plant replicates) but these read sequences were $15 \mathrm{nt}$ and $16 \mathrm{nt}$ in length, no corresponding to STVderived vsiRNAs (Supplementary file 3). vsiRNAs are generated by the RNA silencing defence mechanism and are potentially damaging for the infected plants since they can match host nucleotide sequences and modulate the expression of the corresponding genes (Ding and Voinnet 2007; Huang et al. 2016). For example, vsiRNAs derived from the acute viruses CMV and TYLCV regulate the expression of the host genes CHL1 and SIKNR1, respectively, and induce plant symptoms (Smith et al. 2011; Yang et al. 2019). The low production of STV-derived vsiRNAs might explain the absence of plant symptoms in STV-infected tomato plants (Elvira-González et al. 2018; Puchades et al. 2017). Some authors reported also low concentrations of

Table 2 Differential expression of miRNAs between STV-infected and uninfected tomato plants $($ FDR $<0.05)$

\begin{tabular}{lllllr}
\hline Mature miRNA & Chromosome & Strand & Sequence & Log2FoldChange & FDR \\
\hline stu-miR398a-3p & JH138006.1 & + & UAUGUUCUCAGGUCGCCCCUG & 4,48 & 4 E-07 \\
stu-miR398a-5p & JH138006.1 & + & GGGUUGAUUUGAGAACAUAUG & 4,85 & $4,4 \mathrm{E}-05$ \\
stu-miR3627-3p & JH137794.1 & - & AAGUGCCUCUGUCUUUCGACA & 3,66 & $8,8 \mathrm{E}-05$ \\
sly-miR169e-3p & SL2.40ch08 & + & UGGCAAGCAUCUUUGGCGACU & $-3,76$ & 0,00739 \\
stu-miR319-3p & JH137816.1 & + & UUGGACUGAAGGGUUCCCUUC & 1,66 & 0,04927 \\
\hline
\end{tabular}


a

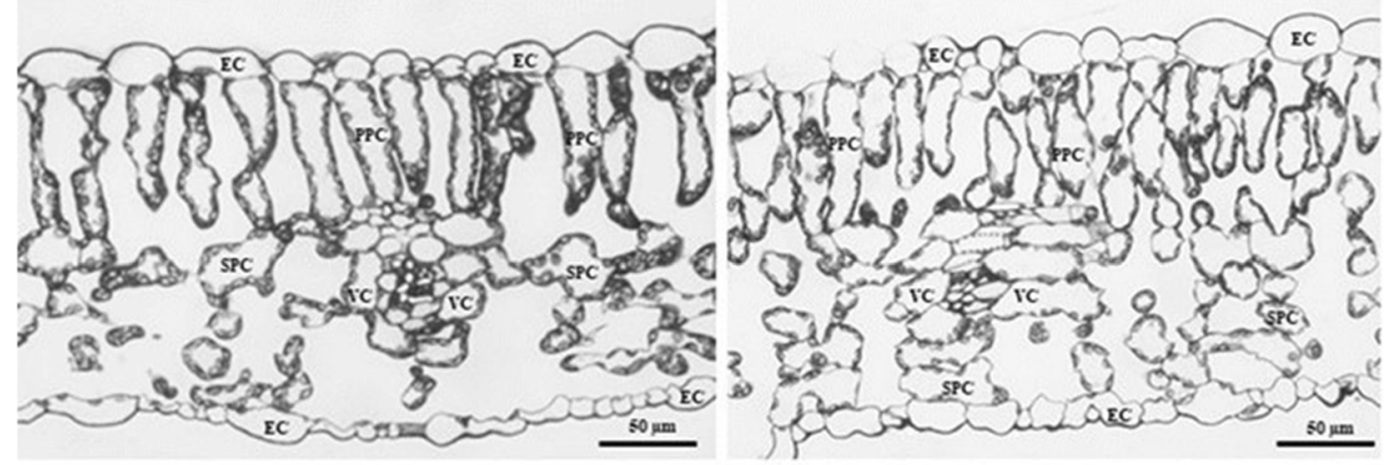

b
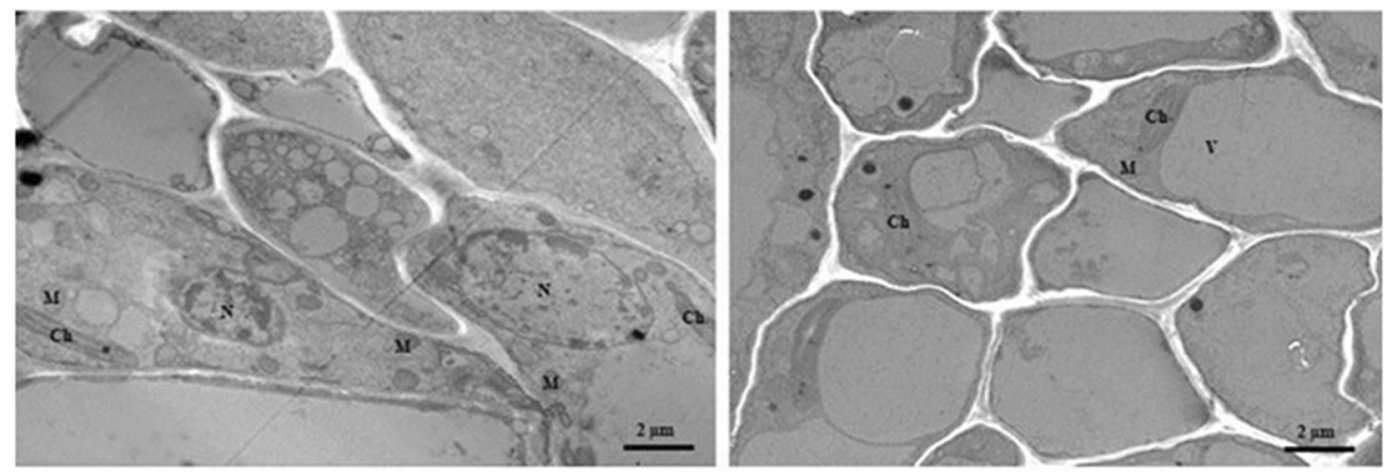

C
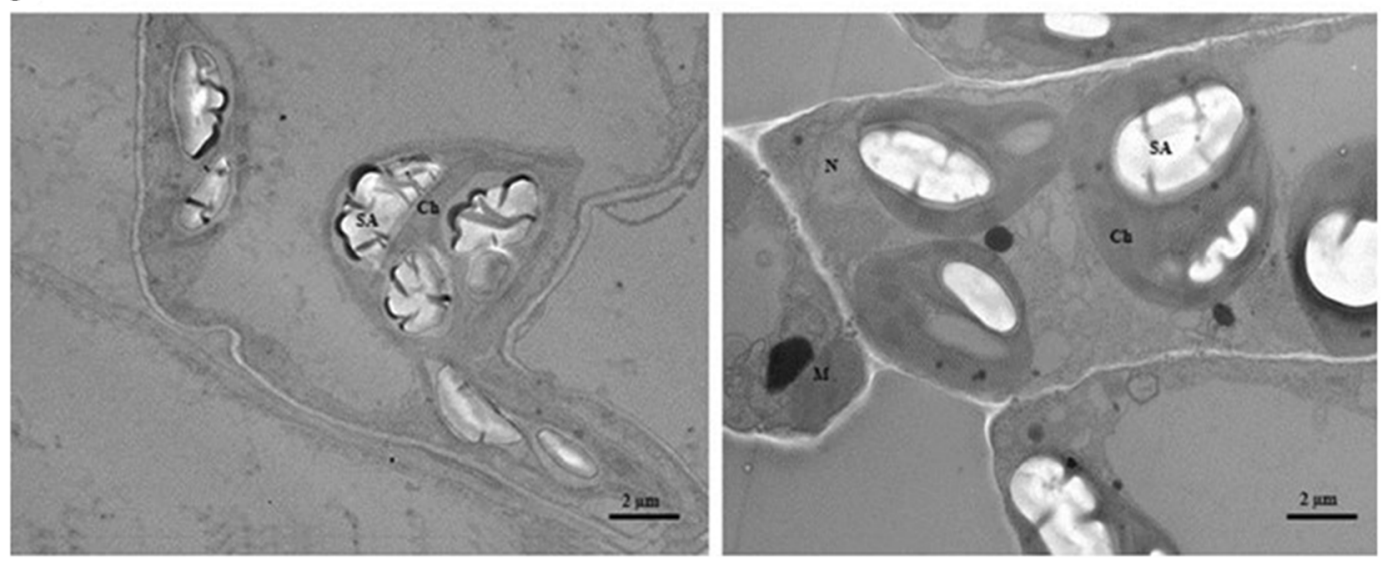

Fig. 1 Optical microscope (Panel a) and TEM micrographs (Panels b and c) showing histological sections of STV-infected and uninfected tomato plants (left and right part of panels, respectively). Panel c shows chloroplast with starch accumulation in both STV-infected

STV-derived sviRNAs which could change depending on co-infection with acute viruses (Fukuhara et al. 2019; Alcala-Briseno et al. 2017; Muñoz-Adalia et al. 2018; Niu et al. 2017; Padmanabhan et al. 2015a; Padmanabhan et al. 2015b; Turco et al. 2018; Xu et al. 2017). Low productions of siRNAs have been reported for some persistent plant virus such as totiviruses and and uninfected parenchymal cells. Abbreviations: Ch (Chloroplast), EC (Epithelial cells), M (Mitochondria), N (Nucleus), PPC (Palisade parenchyma cells), SA (Starch grains), SPC (Spongy parenchyma cells), V (Vacuole) and VC (Vascular cells).

partitiviruses which are phylogenetically related to STV (Sabanadzovic et al. 2009). The low production of siRNAs for some persistent viruses, in contrast to acute viruses, could be due to low viral replication rates and/or that replication occurs into the virus particle so the viral intermediate-replication dsRNAs are not exposed to the plant RNA silencing machinery (Turco et al. 2018). The 
first hypothesis is more plausible since STV showed lower viral titres than viruses such as CMV or pepino mosaic virus (Elvira-González et al. 2018) and no viral particles were visualized by TEM neither from ultra-thin sections nor from virion purified extracts of STVinfected plants (Sabanadzovic et al. 2009).

Optical microscopy and TEM analysis of different plant tissue sections revealed no noticeable ultrastructural changes in STV-infected tomato leaf tissues respect to non-infected tomato. Figure 1 shows one of these tissue sections. No over-disruption of leaf tissues or necrosis was observed in semi-thin sections under optical microscopy (Fig. 1, panel a). TEM of ultra-thin sections did not show any typical alteration produced by acute viral infections such as mitochondrion or chloroplast modifications, unusual starch accumulation in chloroplasts, cytoplasmic vesiculation or presence of tubular structures (Fig.1. Panels b and c). For example, cucumber green mottle mosaic virus causes mitochondrial atrophy (Šutić and Sinclair 1991), torrado tomato virus mitochondrial proliferation and hypertrophy (Alfaro-Fernández et al. 2010), barley stripe mosaic virus chloroplast deformation with cytoplasmic and peripheral invaginations (Jin et al. 2018) and CMV starch accumulation in chloroplasts (Zhao et al. 2016). In this study, starch accumulation was observed in both in STV-infected and uninfected tomato parenchymal cells (Fig. 1, panel c). Some plant alterations produced by acute viruses are related to viral functions such as the generation of cytoplasmic vesicles involved in virus replication (Medina et al. 2003) and tubular structures derived of cell cytoskeleton that are related to cell-tocell virus movement (Liu et al. 2011).

Overall, our results revealed a complex interaction between STV and its host tomato. STV infection induces alterations of the accumulation pattern of some plant miRNAs which are involved in crucial cell pathways, but it was not reflected in cell ultra-structural changes in foliar tissues and plant symptoms. To our knowledge, this is the first report of differential expression of host miRNAs in plants infected with a persistent virus. There is scarce information about the morphological (macroscopic or microscopic) changes induced by differential expression of miRNAs which might regulate different plant genes involved in multiple cellular pathways. Neither ultra-structural nor morphological changes have been previously reported for sly-miR169e-3p and stu-miR319$3 p$ differential expression, but they seem to be involved in the plant response to salt and temperature stress (Blevins et al. 2011; Chaves et al. 2015; Zhao et al. 2017). MiRNAs expressed differentially in STV-infected tomato plants might confer tolerance to several stress conditions as others cryptic viruses, but without inducing apparent ultra-structural changes. In this mutualistic relationship, the STV-infected plants might have some advantages under stress conditions. A recent study suggested a mutualistic relationship between STV and its host by increasing the height, production and germination rate of the STV-infected tomato plants, although these data lack statistical support (Fukuhara et al. 2019). This study also showed changes in the expression of some tomato genes involved in the biosynthesis of the ethylene which modulates fruit production and plant architecture (Fukuhara et al. 2019). One of these genes encodes for the Ethylene Responsive Element Binding Protein, a transcription factor which could be regulated for some of the miRNAs differentially accumulated in STV-infected plants described here. Finally, the scant production of vsiRNAs could be related to the low rates of STV replication and the absence of plant symptoms.

Here we studied the effect of STV in single infections in tomato plants. However, STV is frequently detected in mixed infections with other viruses in tomato crops. So further studies are necessary to understand the effect of STV when other viruses are co-infecting the plant and the interactions between these viruses.

\begin{tabular}{ll}
\multicolumn{2}{l}{ Abbreviations } \\
STV & southern tomato virus \\
dsRNA & double-strand RNA \\
miRNA & plant endogenous microRNA \\
siRNAs & Small interfering RNAs \\
sRNA & small RNA \\
CMV & cucumber mosaic virus \\
TYLCV & tomato yellow leaf curl virus \\
RT-qPCR & Quantitative reverse transcription PCR \\
GO & Gene Ontology \\
TEM & Transmission electron microscopy \\
nt & nucleotide
\end{tabular}

Acknowledgements This research was supported by the INIA project E-RTA2014-00010-C02 co-funded by FEDER 2014-2020 funds. Small RNA analysis was conducted in the Supercomputational and Bioinnovation Center from University of Málaga, Spain. In special, we thank to Drs. Pepi Gómez and Rocio Bautista for their technical assistance and interpretation of Small RNA results. 
Author's contributions LEG performed most of the experiments and data analysis. VM was the responsible of microscopy analysis. LG was responsible of experimental design, participated in data analysis, result interpretation and manuscript writing. LR participated in interpretation of results and manuscript writing.

Funding information This research was supported by the INIA project E-RTA2014-00010-C02 co-funded by FEDER 20142020 funds.

Compliance with ethical standards This research article is not submitted elsewhere for publication and complies with the Ethical Rules applicable for this journal.

Conflict of interest The authors declare that they have no conflict of interest.

Ethical approval This article does not contain any studies with human participants or animals performed by any of the authors. Therefore, informed consent was not required for this work.

Human participants and/or animals This article does not contain any studies with human participants or vertebrate animals.

Informed consent All authors have approved the manuscript and agree to submission to European Journal of Plant Pathology.

\section{References}

Alcala-Briseno, R. I., Coskan, S., Londono, M. A., \& Polston, J. E. (2017). Genome sequence of southern tomato virus in asymptomatic tomato 'Sweet Hearts'. Genome Announcements, 5(7). https://doi.org/10.1128/genomeA.01374-16.

Alfaro-Fernández, A., Medina, V., Córdoba-Sellés, M., Font, M., Jornet, J., Cebrián, M., et al. (2010). Ultrastructural aspects of tomato leaves infected by tomato torrado virus (ToTV) and coinfected by other viruses. Plant Pathology, 59(2), 231-239.

Blevins, T., Rajeswaran, R., Aregger, M., Borah, B. K., Schepetilnikov, M., Baerlocher, L., Farinelli, L., Meins F Jr, Hohn, T., \& Pooggin, M. M. (2011). Massive production of small RNAs from a non-coding region of cauliflower mosaic virus in plant defense and viral counter-defense. Nucleic Acids Research, 39(12), 5003-5014.

Chaves, S., Fernandes-Brum, C., Silva, G., Ferrara-Barbosa, B., Paiva, L., Nogueira, F., et al. (2015). New insights on Coffea miRNAs: Features and evolutionary conservation. Applied Biochemistry and Biotechnology, 117(4), 879-908.

Ding, S., \& Voinnet, O. (2007). Antiviral immunity directed by small RNAs. Cell, 130(3), 413-426.

Dunoyer, P., \& Voinnet, O. (2005). The complex interplay between plant viruses and host RNA-silencing pathways. Current Opinion in Plant Biology, 8(4), 415-423.

Elvira-González, L., Puchades, A., Carpino, C., Alfaro-Fernandez, A., Font-San-Ambrosio, M., Rubio, L., et al. (2017). Fast detection of southern tomato virus by one-step transcription loop-mediated isothermal amplification (RT-LAMP). Journal of Virology Methods, 241, 11-14.

Elvira-González, L., Carpino, C., Alfaro-Fernández, A., Font-San Ambrosio, M. I., Peiró, R., Rubio, L., et al. (2018). A sensitive real-time RT-PCR reveals a high incidence of southern tomato virus (STV) in Spanish tomato crops. Spanish Journal of Agricultural Research, 16(3), 1008.

Falgueras, J., Lara, A. J., Fernández-Pozo, N., Cantón, F. R., Pérez-Trabado, G., \& Claros, M. G. (2010). SeqTrim: A high-throughput pipeline for pre-processing any type of sequence read. BMC Bioinformatics, 11(1), 38.

Fukuhara, T., Tabara, M., Koiwa, H., \& Takahashi, H. (2019). Effect of asymptomatic infection with southern tomato virus on tomato plants. Archive of Virology, 1-10. https://doi. org/10.1007/s00705-019-04436-1

Gandía, M., Bernad, L., Rubio, L., \& Duran-Vila, N. (2007). Host effect on the molecular and biological properties of a citrus exocortis viroid isolate from Vicia faba. Phytopathology, 97(8), 1004-1010.

Huang, J., Yang, M., Lu, L., \& Zhang, X. (2016). Diverse functions of small RNAs in different plant-pathogen communications. Frontiers in Microbiology, 7, 1552.

Jin, X., Jiang, Z., Zhang, K., Wang, P., Cao, X., Yue, N., Wang, X., Zhang, X., Li, Y., Li, D., Kang, B. H., \& Zhang, Y. (2018). Three-dimensional analysis of chloroplast structures associated with virus infection. Plant Physiology, 176(1), 282-294.

Li, F., Pignatta, D., Bendix, C., Brunkard, J. O., Cohn, M. M., Tung, J., et al. (2012). MicroRNA regulation of plant innate immune receptors. Proceedings National Academy of Science US A, 109, 1790-1795.

Liu, C., Ye, L., Lang, G., Zhang, C., Hong, J., \& Zhou, X. (2011). The VP37 protein of broad bean wilt virus 2 induces tubulelike structures in both plant and insect cells. Virus Research, 155(1), 42-47.

Liu, S., Zhou, J., Hu, C., Wei, C., \& Zhang, J. (2017). MicroRNAmediated gene silencing in plant defense and viral counterdefense. Frontiers in Microbiology, 8, 1801.

Marquez, L. M., Redman, R. S., Rodriguez, R. J., \& Roossinck, M. J. (2007). A virus in a fungus in a plant: Three-way symbiosis required for thermal tolerance. Science, 315(5811), 513-515.

Martin, R. R., Zhou, J., \& Tzanetakis, I. E. (2011). Blueberry latent virus: An amalgam of the Partitiviridae and Totiviridae. Virus Research, 155(1), 175-180.

Medina, V., Rodrigo, G., Tian, T., Juarez, M., Dolja, V. V., Angeles-Achon, M., et al. (2003). Comparative cytopathology of Crinivirus infections in different plant hosts. Annals of Applied Biology, 143(1), 99-110.

Muñoz-Adalia, E. J., Diez, J. J., Fernández, M. M., Hantula, J., \& Vainio, E. (2018). Characterization of small RNAs originating from mitoviruses infecting the conifer pathogen Fusarium circinatum. Archives of Virology, 163(4), 1009-1018.

Naqvi, A. R., Haq, Q. M., \& Mukherjee, S. K. (2010). MicroRNA profiling of tomato leaf curl New Delhi virus (TOLCNDV) infected tomato leaves indicates that deregulation of mir159/ 319 and mir172 might be linked with leaf curl disease. Virology Journal, 7(1), 281.

Niu, D., Wang, Z., Wang, S., Qiao, L., Zhao, H. (2015). Profiling of small RNAs involved in plant-pathogen interactions. Plant Gene Silencing. Edited by Anonymous Springer, 61-79. 
Niu, X., Sun, Y., Chen, Z., Li, R., Padmanabhan, C., Ruan, J., et al. (2017). Using small RNA-seq data to detect siRNA duplexes induced by plant viruses. Genes, 8(6), 163.

Padmanabhan, C., Zheng, Y., Li, R., Fei, Z., \& Ling, K. S. (2015a). Complete genome sequence of southern tomato virus naturally infecting tomatoes in Bangladesh. Genome Announcements, 3. https://doi.org/10.1128/genomeA.01522-15.

Padmanabhan, C., Zheng, Y., Li, R., Sun, S. E., Zhang, D., Liu, Y., et al. (2015b). Complete genome sequence of southern tomato virus identified in China using next-generation sequencing. Genome Announcements, 3. https://doi.org/10.1128 /genomeA.01226-15.

Parish, R., Li, S.F. (2012). Transgenic plant male sterility. US Patent App, 13/509, 265

Puchades, A., Carpino, C., Alfaro-Fernandez, A., Font-SanAmbrosio, M., Davino, S., Guerri, J., et al. (2017). Detection of southern tomato virus by molecular hybridisation. Annals of Applied Biology, 171(2), 172-178.

Rahman, R. U., Gautam, A., Bethune, J., Sattar, A., Fiosins, M., Magruder, D. S., et al. (2018). Oasis 2: Improved online analysis of small RNA-seq data. BMC Bioinformatics, 19, 54.

Roossinck, M. J. (2010). Lifestyles of plant viruses. Philosophical Transactions of the Royal Society of London B, Biological Sciences, 365(1548), 1899-1905.

Roossinck, M. J. (2011). The good viruses: Viral mutualistic symbioses. Nature Reviews Microbiology, 9(2), 99-108.

Sabanadzovic, S., Valverde, R. A., Brown, J. K., Martin, R. R., \& Tzanetakis, I. E. (2009). Southern tomato virus: The link between the families Totiviridae and Partitiviridae. Virus Research, 140(1), 130-137.

Smith, N. A., Eamens, A. L., \& Wang, M. (2011). Viral small interfering RNAs target host genes to mediate disease symptoms in plants. PLoS Pathogens, 7(5), e1002022.

Sun, G. (2012). MicroRNAs and their diverse functions in plants. Plant Molecular Biology, 80(1), 17-36.

Šutić, D. D., \& Sinclair, J. B. (1991). Anatomy and physiology of diseased plants. CRC press, 232
Tagami, Y., Inaba, N., Kutsuna, N., Kurihara, Y., \& Watanabe, Y. (2007). Specific enrichment of miRNAs in Arabidopsis thaliana infected with tobacco mosaic virus. DNA Research, 14(5), 227-233.

Turco, S., Golyaev, V., Seguin, J., Gilli, C., Farinelli, L., Boller, T., et al. (2018). Small RNA-omics for virome reconstruction and antiviral defense characterization in mixed infections of cultivated Solanum plants. Molecular Plant-Microbe Interaction, 31(7), 707-723.

Verbeek, M., Dullemans, A., Espino, A., Botella, M., AlfaroFernández, A., \& Font, M. I. (2015). First report of southern tomato virus in tomato in the Canary Islands, Spain. Journal of Plant Pathology, 97(2), 392.

Wang, M., Masuta, C., Smith, N. A., \& Shimura, H. (2012). RNA silencing and plant viral diseases. Molecular Plant-Microbe Interaction, 25(10), 1275-1285.

Xu, S., Liu, N., Mao, W., Hu, Q., Wang, G., \& Gong, Y. (2016). Identification of chilling-responsive microRNAs and their targets in vegetable soybean (Glycine max L.). Scientific Reports, 6, 26619.

Xu, C., Sun, X., Taylor, A., Jiao, C., Xu, Y., Cai, X., et al. (2017). Diversity, distribution, and evolution of tomato viruses in China uncovered by small RNA sequencing. Journal Virology, 91(11). https://doi.org/10.1128/JVI.00173-17 Print 2017 Jun 1.

Yang, Y., Liu, T., Shen, D., Wang, J., Ling, X., Hu, Z., Chen, T., Hu, J., Huang, J., Yu, W., Dou, D., Wang, M. B., \& Zhang, B. (2019). Tomato yellow leaf curl virus intergenic siRNAs target a host long noncoding RNA to modulate disease symptoms. PLoS Pathogens, 15(1), e1007534.

Zhao, J., Zhang, X., Hong, Y., \& Liu, Y. (2016). Chloroplast in plant-virus interaction. Frontiers in Microbiology, 7, 1565.

Zhao, G., Yu, H., Liu, M., Lu, Y., \& Ouyang, B. (2017). Identification of salt-stress responsive microRNAs from Solanum lycopersicum and Solanum pimpinellifolium. Plant Growth Regulation, 83(1), 129-140.

Ziemann, M., Kaspi, A., \& El-Osta, A. (2016). Evaluation of microRNA alignment techniques. RNA, 22(8), 1120-1138. 